\title{
What Are We Doing and Why
}

\author{
Are We Doing It? A Preface
}

Modernism, postmodernism, discourse, deconstruction, hegemony, hybridity, hermeneutics, semiotics, episteme. Even for someone trained in cultural theory these terms can be daunting. For the novice, they can be downright alienating. This book has two goals: to define and explain the basics of cultural theory, or postmodernism, and to demonstrate its usefulness in interpreting nineteenth- and twentieth-century Latin America.

This book grows out of an undergraduate seminar we teach at Furman University, a liberal arts school in South Carolina. We find that most of our students entering the seminar have heard of postmodernism and cultural theory but lack a working knowledge of them. We are happy to report that none of them has left ignorant, although, admittedly, not all of them have agreed with us as to cultural theory's explanatory merits. In fact, some have left firmly opposed to it, choosing to retreat to the safety of modernity; others have left unsure, waiting for more information to declare a verdict. Still others have strongly accepted its claims and now see themselves and their world in a new way. It is not of great concern to us whether our students agree with us by the end of the course. We simply want to make cultural theory and postmodernism accessible to them so they can decide for themselves. The same objective drives this book.

Its structure follows closely that of our seminar, which we designed to ease the encounter with cultural theory and postmodernism. A main introductory section lays out some central issues. The remainder is divided into two parts. The first is dedicated to theory and consists of brief excerpts from key works in cultural theory. Some of these address specifically Latin America; others are more general. The second part consists of excerpts from 
some of Latin America's principal writers in the nineteenth and twentieth centuries, including Domingo Sarmiento, José Martí, Rómulo Gallegos, Elena Garro, and Che Guevara. Anyone familiar with Latin America will recognize these authors as key figures in Latin American history and/or literature. Indeed, their writings commonly appear in anthologies. So what makes our approach different? Why have we included the same authors that anthologists have selected repeatedly? We will show that what matters is not what is read, but how it is read. Using our section on theory as a guide, we will demonstrate how to read these works from a cultural theory perspective. We will then show how this approach results in new interpretations of modern Latin American history and culture.

The introductory sections of the book prepare the reader to interpret its deliberate mixture of primary and secondary sources that cuts across the traditional theory/text hierarchy. We should point out here that it is not our goal to offer a comprehensive survey of particular time periods, authors, or literary styles. We leave those goals to anthologies and historical surveys. To that end, we have divided our coverage into only five areas:

I. Liberalism (mid-to-late nineteenth century)

2. Nationalism (late nineteenth through mid-twentieth century)

3. Socialism (I959-1989)

4. Magical realism (I960s and I970s)

5. Testimonials (I970s-I990s)

These areas are ordered chronologically and cover most of Latin America's modern era, which dates back to independence from Spain in the early nineteenth century (with a few exceptions, like Brazil and Cuba). They obviously are not comprehensive, and they represent an admixture of historical eras and literary styles. We have made these choices because they allow us to explain cultural studies and then apply its theories to a series of readings in the confines of a short book.

Our selections have another objective, which is to show the prevailing trend in Latin American intellectual and political circles over the past two centuries to incorporate a broader swath of the population into the center of power. Authors in the mid-nineteenth century were typically privileged white, propertied males, but by the end of the twentieth century, the definitive protagonist had become dark-skinned, poor, and female. But our cultural studies reading of this progression will illustrate how ideologies and power structures can betray authorial intentions. Sometimes, attempts at liberation contain elements of exclusion and hierarchy. 
The excerpted writings are drawn from a variety of genres, including but not limited to essays, novels, short stories, and personal testimonies. We have also included film analyses and other secondary critical essays on primary texts. Each of these is preceded by a brief, or not so brief, introduction written by us to provide some guidance for our readers. At the end of the book, we offer a few concluding thoughts inspired by questions typically asked by our students as we approach the end of our term together.

We assume that readers of this book already understand the basic contours of Latin American history, but such knowledge is not essential. For those who do not know Latin America or who are interested in a refresher, we recommend reading a historical overview alongside this book, such as John Charles Chasteen's Born in Blood and Fire (New York: Norton, 2006) or Will Fowler's Latin America I800-2000 (New York: Oxford UP, 2002).

The seminar experience has been a constant source of intellectual growth and pleasant interaction. We and the students who assisted in writing this book have enjoyed the challenge of trying to recreate the seminar here. We hope the following pages demonstrate and perpetuate the sentiment that went into it. 
